\title{
Aesthetics training facility unveils state-of-the-art renovation
}

Mapperley Park has now formally rebranded to Mapperley Park Aesthetics Training Academy with a total renovation of their Nottingham-based premises. The team marked the relaunch with an invitation-only VIP event on 18 August held at the academy with a talk from leading authority on lasers, Professor Kayvan Shokrollahi, offering perspectives on laser treatments, as well as legal and training insights.

Established in 1993, Mapperley Park provides training from industry experts, as well as offering a large portfolio of courses within the aesthetic sector. The Academy has recently undergone a complete transformation to create a state-of-the-art.

During the evening, guests were given the opportunity to network with like-minded industry professionals, as well as being offered a tour of the facility.

Delegates were given an introduction to Mapperley Park's wide range of laser and injectable courses that are designed to enable practitioners to develop their knowledge, understanding and confidence. The team was also proud to announce the launch of three innovative and accredited BTEC qualifications in lasers that launched in August,

\section{Quality cabinetry in over 300 colours}

According to a poll, $82 \%$ of people think appearance affects customer service, which is a vital statistic considering $91 \%$ of unhappy customers are likely to seek the services of a competitor.

To ensure your patients are satisfied with your practice, your choice of dental cabinetry is paramount.

The modern Classic C3000 range of dental cabinets from Tavom UK boasts a contemporary and durable design to meet these demands, and offers hook and block drawer slides, adjustable levelling feet and mobile units to meet ergonomic requirements.

The range is also easy to clean and HTM-01 infection control compliant, to ensure that the highest standard can be maintained in your practice.

Thus, if you are looking to boost your business and increase patient satisfaction through quality dental cabinetry, Tavom UK has the solution - and it's available in over 300 colours.

To improve the appearance of your practice with the help of Tavom UK, contact the qualified and highly experienced team today.

To see how Tavom can transform your dental practice, call 0870 7521121 or visit the Tavom UK website www.tavomuk.com.

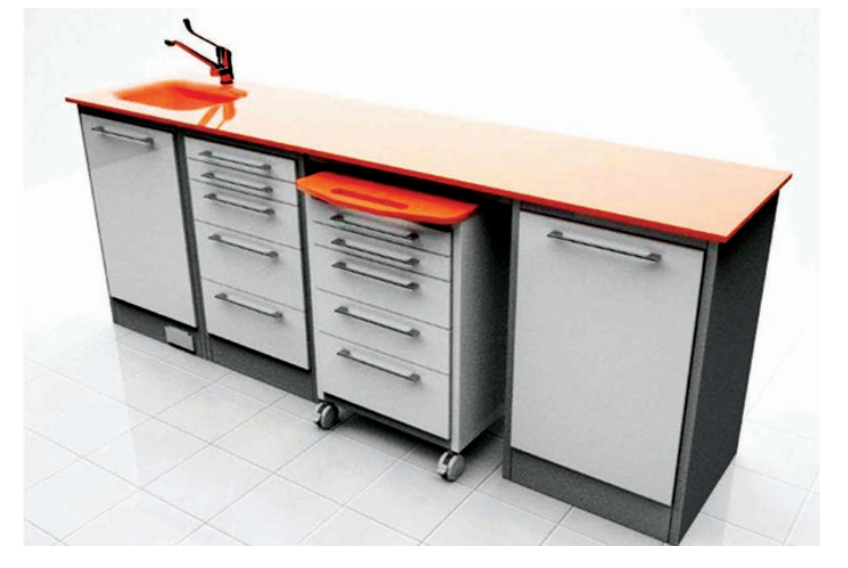

the first of their kind at this level in the UK. For further information about Mapperley Park Aesthetics Training Academy and the courses that it offers visit: www.mapperleypark.co.uk.

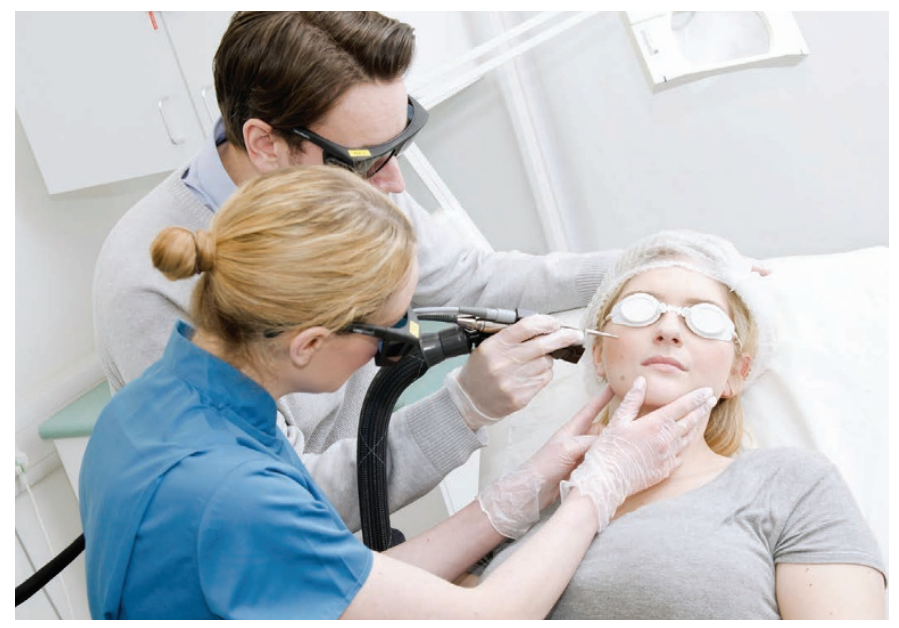

\section{Uniquely formulated varnish for hypersensitivity relief}

NUPRO 5\% White Varnish from Dentsply Sirona promotes rapid fluoride release giving fast and effective relief from hypersensitivity. Applied with a brush in a thin layer, the fluoride varnish provides a highly concentrated temporary dose of fluoride to the tooth surface by sealing dentinal tubules.

Most fluoride varnishes are lacquers containing 5\% fluoride in a colophony/rosin base. In contrast, NUPRO 5\% Sodium Fluoride White Varnish is formulated with a hydrogenated rosin and urethane resin base.

Designed to minimise clumping, with no dripping or stringing, NUPRO varnish eliminates some of the biggest frustrations dental professionals experience when using fluoride varaanish. Flexible packaging allows the user to choose how to hold the unit dose: it can be snapped on the prophy grip, held between the fingers or rested on the dental tray. Easy to handle and apply, dentists and hygienists will save time and effort as it can be applied without needing to dry the teeth first.

Developed with patients in mind, NUPRO White Varnish enables a shorter wear time compared to other leading varnish brands and patients can eat and drink after only two hours. Available in a variety of flavours that will appeal to both adults and children, it is also gluten-free to suit those with dietary considerations.

To find out more about NUPRO 5\% White Varnish contact Dentsply Sirona on 08000723313 or visit dentsply.com/en-uk. 